\title{
Should Patients be Routinely Screened for Hepatitis B Serology before the Use of Chemotherapy Due to Solid Organ Tumors?
}

\author{
Murat Pekgöz*1 and Ömer Fatih Ölmez ${ }^{2}$ \\ ${ }^{1}$ Department of Gastroenterology, Medical School, Uludağ University, Turkey \\ ${ }^{2}$ Medical Oncology Department, Medipol University, Turkey
}

Received: 制 August 01, 2018; Published: 制 August 09, 2018

*Corresponding author: Murat Pekgöz, Bolu State Hospital, Department of Gastroenterology, 14300, Bolu, Turkey

\begin{abstract}
Background: The prevalence of chronic hepatitis-B virus (HBV) is highly variable by region in the world. In chronic HBV, most of exacerbations are associated with the interaction of immune response to HBV and virus replication. All kinds of chemotherapy regimens potentially cause HBV replication.
\end{abstract}

Case Report: 58-year-old male patient, non-small cell lung adenocarcinoma was diagnosed. Adjuvant chemotherapy combination including navelbine and cisplatin was initiated for the patient. He admitted with the complaints of weakness and fatique after the one week of the second cure of chemotherapy. On physical examination, oral mucosa, sclera and skin were icteric. HBV-DNA level was measured as > 1000000000 (1 billion) IU/ $\mathrm{mL}$.

Conclusion: Clear benefit or harm of routine hepatitis B screening is controversial during the use of chemotherapy in solid organ tumours. Especially in our country in which HBV prevalence is high, HBV infection screening have to be considered in patients scheduled to receive chemotherapy due to solid organ tumours in terms of HBV reactivation.

Keywords: Hepatitis-B; Chemotherapy; Reactivation

\section{Introduction}

The prevalence of chronic hepatitis-B virus (HBV) is highly variable by region in the world. In chronic HBV, most of exacerbations are associated with the interaction of immune response to HBV and virus replication [1]. Exacerbation is similar to the increase of spontaneous immune response to HBV as those in HBeAg seroconversion. HBV exacerbation is characterized by the sudden elevated of serum aminotransferase level with or without clinical symptoms [2]. Priorly, HBV-DNA level frequently increases. Also, increase in alpha fetoprotein levels can be seen in hepatitis exacerbations [3]. Hepatitis exacerbation occurs in cases with chronic HBV rather than cases with chronic hepatitis C. Although its reason cannot be fully explained, the immune response can play a major role over the disease activity in HBV cases. The risk of reactivation is about $20-50 \%$ in HBsAg positive cases. All kinds of chemotherapy regimens potentially cause HBV replication [4]. Clear benefit or harm of routine hepatitis B screening is controversial during the use of chemotherapy in solid organ tumours [5]. By this case report and literature review, we aimed to point out the issue of hepatitis B reactivation and acute liver failure in a patient treated with chemotherapy due to lung adenocarcinoma.

\section{Case Presentation}

Biopsy was performed by interventional radiology department in a 58-year-old male patient because of the detection a of $5-\mathrm{cm}$ mass in apical segment of left lung lobe during the examination which made for the complaint of shortness of breath. Non-small cell adenocarcinoma was diagnosed, and mediastinal and distant metastases was not found by the staging tests. The patient received left upper lobectomy and mediastinal sampling. Adjuvant chemotherapy combination including navelbine and cisplatin was initiated for the patient with T2aN1M0 (stage IIA) based on the postoperative staging. His medical history was unremarkable except that Type-2 Diabetes Mellitus and inactive HBV carrier as comorbid systemic diseases. HBV-DNA level was negative and transaminase levels were normal before chemotherapy. He admitted to department of medical oncology with the complaints of weakness and fatigue after the one week of the second cure of chemotherapy.

On physical examination, the patient with moderate general condition was cooperative and had clear consciousness. His oral 
mucosa, sclera and skin were icteric. Abdominal examination revealed a sensitivity to blunt percussion of liver. Laboratory values included total leukocyte (WBC): $7040 \mathrm{~K} / \mu \mathrm{l}$, haemoglobin (Hgb): $11.9 \mathrm{~g} / \mathrm{dL}$, thrombocyte (PLT): $117000 \mathrm{~K} / \mu \mathrm{L}$, total bilirubin (T.Bil): $7.7 \mathrm{mg} / \mathrm{dL}$, direct bilirubin (D.Bil): $5.7 \mathrm{mg} / \mathrm{dL}$, aspartate aminotransferase (AST): $615 \mathrm{IU} / \mathrm{L}$, alanine aminotransferase (ALT): 493 IU/L, gamma glutamyl transpeptidase (GGT): 350 IU/L, alkaline phosphatase (ALP): $128 \mathrm{IU} / \mathrm{L}$, alpha fetoprotein (AFP): $25.1 \mathrm{ng} / \mathrm{mL}$, prothrombin time (PT): 21, international normalized ratio (INR): 1,9. Hepatitis markers were as following; positive HBsAg, negative Anti-HBs, positive Anti-Hbc IgG, negative $\mathrm{HBeAg}$, positive AntiHBe, negative Anti-HDV and negative Anti-HCV. HBV-DNA level was measured as $>1000000000$ (1 billion) IU/mL (Table 1). Liver and bile tract were normal according to abdominal ultrasonography.

Table 1: The course of laboratory values.

\begin{tabular}{|c|c|c|c|}
\hline & BASELINE & 3-MONTH & 6-MONTH \\
\hline WBC $(\mathrm{K} / \mu \mathrm{l})$ & 7040 & 8200 & 9680 \\
\hline HGB (g/dL) & 11,9 & 13,1 & 13 \\
\hline PLT $(K / \mu \mathrm{L})$ & 117000 & 213000 & 234000 \\
\hline AST (IU/L) & 615 & 13 & 15 \\
\hline ALT (IU/L) & 493 & 20 & 17 \\
\hline T.Bil (mg/dL) & 7,7 & 0,4 & 0,4 \\
\hline D.Bil (mg/dL) & 5,7 & 0,2 & 0,1 \\
\hline $\operatorname{ALP}(\mathrm{IU} / \mathrm{L})$ & 128 & 52 & 50 \\
\hline GGT (IU/L) & 350 & 38 & 35 \\
\hline PT & 21 & 11 & 10 \\
\hline INR & 1,9 & 1 & 0,8 \\
\hline $\operatorname{AFP}(\mathrm{ng} / \mathrm{mL})$ & 25.1 & 1,78 & 1,39 \\
\hline HBV-DNA & $>1 \times 10^{9}$ & Negative & Negative \\
\hline$(\mathrm{IU} / \mathrm{mL})$ & & & \\
\hline
\end{tabular}

Acute exacerbation of chronic hepatitis B and acute liver failure due to the chemotherapy-induced immunosuppression was diagnosed. The patient was hospitalized and acute liver failure therapy together with antiviral therapy in the form of 0.5 mg entecavir once a day were initiated. In a short time, general condition of the patient whose liver function tests and liver enzymes fell to normal levels is improved. At the first month of treatment, HBV-DNA decreased more than 6 logs and it was negative at the third month. Then, the patient was followed clinically.

\section{Discussion}

There is limited evidence related to the clear benefit or harm of routine hepatitis B screening in cases treated with cytotoxic or immunosuppressive therapy for solid organ tumour [5]. With regard to chronic hepatitis B, serologic tests for hepatitis B screening are recommended prior to initiation of cytotoxic or immunosuppressive therapy (patients receiving chemotherapy for malignant diseases and receiving immunosuppressive for organ transplantation, rheumatologic or gastrointestinal diseases) in a guidance reported in 2012 by European Association for the Study of the Liver (EASL) [6]. Optimal duration of prophylactic treatment is not exactly clear in cases diagnosed with chronical hepatitis B during or before the cytotoxic chemotherapy or immunosuppressive therapy. For the cases whose baseline HBV-DNA level less than $2000 \mathrm{IU} / \mathrm{ml}$, prophylaxis should be continued for at least 6 months following the completion of chemotherapy or immunosuppressive therapy.

If HBV-DNA is above $2000 \mathrm{IU} / \mathrm{ml}$, it should be continued until the absolute result is achieved like as in immunocompetent patients. Cases with negative baseline HBV-DNA can be treated with short-term lamivudine or telbivudine therapy ( $<12$ months). If long-term therapy is scheduled, tenofovir or entecavir should be preferred. Interferon therapy should be avoided because of its suppressive effect on bone marrow. During the exacerbation, symptoms such as weakness, lack of appetite and nausea may appear in some patients. Whereas in severe exacerbations, more serious symptoms such jaundice and hepatic decompensation or death can be seen. Liver functions tests and prothrombin time of patients should be closely monitored for liver failure [7]. Serologic tests including HbsAg, anti-Hbc and anti-Hbs are recommended for patients who will be screened [6].

\section{Conclusion}

In conclusion, HBV infection screening have to be considered in patients scheduled to receive chemotherapy due to solid organ tumours in terms of HBV reactivation.

\section{References}

1. Hwang JP, Lok AS (2014) Management of patients with hepatitis B who require immunosuppressive therapy. Nature Reviews Gastroenterology \& Hepatology 11(4): 209-219.

2. Wei Lun Tsai, Wei Chi Sun, Jin Shiung Cheng (2015) Chronic Hepatitis B with Spontaneous Severe Acute Exacerbation. International Journal of Molecular Sciences 16(12): 28126-28145.

3. Ming Ling Chang, Yun Fan Liaw (2014) Hepatitis B flares in chronic hepatitis B: Pathogenesis, natural course, and management. Journal of Hepatology 61: 1407-1417.

4. Liu Chun Jen, Chen Pei Jer, Chen Ding Shinn, kao JH (2013) Hepatitis B virus reactivation in patients receiving cancer chemotherapy: natural history, pathogenesis, and management. Hepatology Internationa 7: 316-326.

5. Artz AS, Somerfield MR, Feld JJ, Guisti IF, Kramer BF, et al. (2010) American Society of Clinical Oncology provisional clinical opinion: chronic hepatitis B virus infection screening in patients receiving cytotoxic chemotherapy for treatment of malignant diseases. Journal of Clinical Oncology 28(19): 3199-3202.

6. (2012) EASL Clinical Practice Guidelines: Management of chronic hepatitis B virus infection. Journal of Hepatology 57: 167-185.

7. Zihao Liu, Lei Jiang, Gehao Liang, Erwei Song, Yubao Zheng, et al. (2017) Hepatitis B Virus Reactivation in Breast Cancer Patients Undergoing Chemotherapy: a review and meta-analysis of prophylaxis management Journal of Viral Hepatitis 24(7): 561-572. 


\section{ISSN: 2574-1241}

DOI: 10.26717/BJSTR.2018.07.001551

Murat Pekgöz. Biomed J Sci \& Tech Res

(C) (i) This work is licensed under Creative

Submission Link: https://biomedres.us/submit-manuscript.php

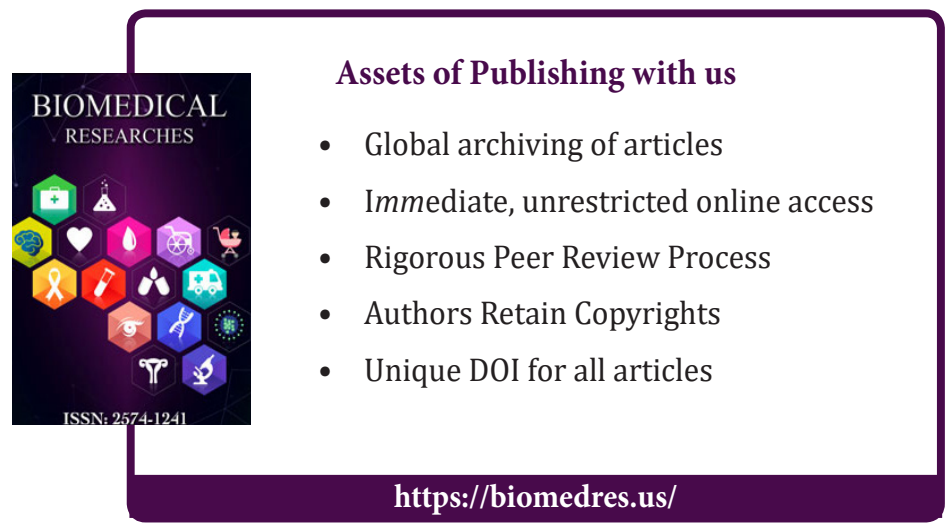

